\title{
Predictive accuracy of Goodsall's rule for fistula-in-ano
}

\author{
U Jayarajah, D N Samarasekera \\ (Index words: Goodsall's rule, simple fistula-in-ano, predictive accuracy)
}

\begin{abstract}
Introduction Successful treatment of fistula-in-ano is sometimes challenging due to difficulty in recognizing the internal opening and the course of the fistula tract. Although Goodsall's rule was accepted in the past, as a method to determine the course of the fistula, recent data have shown conflicting results.
\end{abstract}

Objectives To study the predictive accuracy of Goodsall's rule.

Methods A sample of 212 patients with simple fistulae were studied. Hydrogen peroxide was injected through the external opening and the appearance of air bubbles in the anal canal indicated the location of the internal opening. The morphological parameters including the site and number of internal and external opening/s and the course of the tract were recorded.

Results The median age of the participants was 39 (range, $18-78)$ years. The majority ( $n=167,78.8 \%)$ were males. Of the study group, 63 (29.7\%) had inter-sphincteric fistulae, $114(53.8 \%)$ transphincteric fistulae and 35 (16.5\%) superficial fistulae. The overall predictive accuracy of Goodsall's rule in our patients was $78.3 \%$. Predictive accuracy was significantly associated with type of fistulae with high predictive accuracy seen in superficial fistulae (97.1\%) and inter-sphincteric fistulae (84.1\%) compared to transphincteric fistulae $(69.3 \%)(p=0.001)$. Predictive accuracy was significantly higher in those with an external opening in the midline (98.2\%), $(p<0.001)$.

Conclusions Although Goodsall's rule was not accurate in $22 \%$ of all fistulae, it can be used as a guide in locating the path of the tract and the internal opening in simple fistulae.

Ceylon Medical Journal 2017; 62: 97-99

DOI: http://doi.org/10.4038/cmj.v62i2.8474

\section{Introduction}

Fistula-in-ano is a hollow tract that connects the internal opening inside the anal canal to the external opening in the perianal skin. Successful treatment of fistula-in-ano is sometimes challenging due to the difficulty in precise identification of the course of the fistula. Recognition of both external and internal openings of the fistula tract is necessary for complete identification of the course of the tract. Identification of the external opening is obvious as the patient presents with a discharge through the external opening, but identification of the internal opening may not be straight forward [1]. Several classification systems exist to help clinicians to identify the path of the tract. One such classification is the Park's classification [2].

David Henry Goodsall is well-known for formulation of a rule that defines the course of an anal fistula which is known as "Goodsall's rule". Goodsall's rule states that, if the external opening of the fistula is posterior to the transverse anal line, the fistula probably originates from the dorsal midline, whereas if the external opening is anterior, the tract probably extends directly to the nearest crypt [3]. Although it was universally accepted in the past, there has been conflicting data regarding the predictive accuracy of Goodsall's rule in recent times [1, 4-6]. Understanding the predictive accuracy of Goodsall's rule in various types of anal fistulae will be helpful for surgeons to locate the internal opening and define the fistula tract more precisely. Thus, we attempted to study and scrutinise the predictive accuracy of Goodsall's rule.

\section{Methods}

A retrospective analysis was conducted of patients who underwent surgery for fistula-in-ano from year 2003 to 2015. Records from operating room and patient records which were prospectively entered into a computerised database were analysed. All patients with simple fistulain-ano were included. Those with complex fistulae were not considered for this study. Complex fistulae were defined as fistula associated with multiple tracts, horse shoe fistulae, fistula with long tracts (any tract length> $10 \mathrm{~cm}$ ), fistula with supralevator blind extension and fistula associated with abscess/pus collections [7-9]. Those with recurrent fistula, indeterminate operative findings and fistulae due to secondary causes such as

Department of Surgery, Faculty of Medicine, University of Colombo, Sri Lanka.

Correspondence: DNS, e-mail: <samarasekera58@yahoo.co.uk>. Received 12 December 2016 and revised version accepted 21 March 2017.

This is an open-access article distributed under the terms of the Creative Commons Attribution License, which permits unrestricted use distribution, and reproduction in any medium, provided the original author and source are credited. 
trauma, tuberculosis, Crohn's disease and carcinoma were excluded from the study $(n=19)$.

All examinations and investigations were carried out by a single senior consultant colorectal surgeon. The relevant clinical history, digital examination of the ano-rectum and proctosigmoidoscopy were carried out in all patients. Those who required further assessment before examination under anaesthesia underwent endoanal ultrasonography which was performed using a $12 \mathrm{MHz}$ RU-12 M-RI 360 degree rotating rigid endosonography probe (Olympus, Tokyo, Japan). All patients were assessed in the lithotomy or prone jacknife position depending on the ease of access of the fistula tract and the surgeon's preference. Examination under anaesthesia was done using standard Lockhart Mummery fistula probes and hydrogen peroxide. Hydrogen peroxide was injected through the external opening of the fistula using a cannula and the appearance of air bubbles inside the anal canal indicated the location of the internal opening.

All morphological parameters including site and the number of internal openings, site and the number of external openings, course of the tract, level of the internal opening and associated abscesses were entered into a standardised diagram of the anal sphincter anatomy. Setons were placed in high fistulae. All fistulae were sent for histological evaluation to exclude secondary causes. Ethical clearance was obtained from Ethics Review Committee of National Hospital of Sri Lanka.

Data were analysed using SPSS version 20. Categorical data were expressed using frequency and percentages. Univariate analysis was carried out using Pearson's chi-squared test to look for associations. A $p$ value less than 0.05 was considered as statistically significant.

\section{Results}

Of a total of 235 patients with simple fistulae, 212 were included in the analysis (rate of missing values: $\mathrm{n}=23,9.8 \%$ ). The median age of the participants was 39 (range $=18-78)$ years. The majority $(n=167,78.8 \%)$ of the patients were males. Of the study group, 63 (29.7\%) had intersphincteric fistulae, 114 (53.8\%) transphincteric fistulae and 35 (16.5\%) superficial fistulae. The predictive accuracy of Goodsall's rule in our patients with simple fistulae was $78.3 \%$. The predictive accuracy of Goodsall's rule was not related to gender. Predictive accuracy was significantly associated with the type of fistula with superficial fistulae (97.1\%) and intersphincteric fistulae (84.1\%) having higher predictive accuracy ( $p=0.001$ ). External openings positioned in the midline had a significantly higher predictive accuracy (98.2\% vs. $71.3 \%, p<0.001)$ than those in other positions (Table 1).
Table 1. Goodsall's rule based prediction of the course of fistula and related

\begin{tabular}{|c|c|c|c|c|c|c|}
\hline & & \multicolumn{4}{|c|}{$\begin{array}{c}\text { Course of fistula correctly predicted } \\
\text { by 'Goodsall's Rule' }\end{array}$} & \multirow[t]{3}{*}{$P$ value } \\
\hline & & \multicolumn{2}{|r|}{ Yes } & \multicolumn{2}{|c|}{ No } & \\
\hline & & $N$ & $(\%)$ & $N$ & $(\%)$ & \\
\hline \multirow[t]{2}{*}{ Sex } & Male & 134 & $(80.2)$ & 33 & (19.8) & \multirow[t]{2}{*}{0.187} \\
\hline & Female & 32 & (71.1) & 13 & (28.9) & \\
\hline \multirow[t]{3}{*}{ Type } & Superficial & 34 & $(97.1)$ & 1 & (2.9) & \multirow[t]{3}{*}{0.001} \\
\hline & Inter-sphincteric & 53 & (84.1) & 10 & (15.9) & \\
\hline & Trans-sphincteric & 79 & $(69.3)$ & 35 & (30.7) & \\
\hline \multirow{6}{*}{$\begin{array}{l}\text { Position of external } \\
\text { opening }\end{array}$} & Midline anterior & 12 & $(100.0)$ & 0 & $(0.0)$ & \multirow[t]{6}{*}{$<0.001$} \\
\hline & Midline posterior & 42 & $(97.7)$ & 1 & $(2.3)$ & \\
\hline & Left anterior & 30 & (81.1) & 7 & (18.9) & \\
\hline & Left posterior & 29 & $(67.4)$ & 14 & (32.6) & \\
\hline & Right posterior & 37 & $(74.0)$ & 13 & (26.0) & \\
\hline & Right anterior & 16 & (59.3) & 11 & $(40.7)$ & \\
\hline \multirow{2}{*}{$\begin{array}{l}\text { Position of external } \\
\text { opening }\end{array}$} & Midline & 54 & (98.2) & 1 & $(1.8)$ & \multirow[t]{2}{*}{$<0.001$} \\
\hline & Other & 112 & (71.3) & 45 & (28.7) & \\
\hline \multirow{2}{*}{$\begin{array}{l}\text { Position of external } \\
\text { opening }\end{array}$} & Anterior & 58 & (76.3) & 18 & (23.7) & \multirow[t]{2}{*}{0.600} \\
\hline & Posterior & 108 & (79.4) & 28 & (20.6) & \\
\hline
\end{tabular}

\section{Discussion}

In our study, the predictive accuracy for simple fistulae was $78.3 \%$. Fistulae with an anterior external opening had a predictive accuracy of $76.3 \%$ while those with a posterior opening had a predictive accuracy of $79.4 \%$. The difference was not statistically significant. Goodsall's rule was able to predict the internal opening in $97.1 \%$ of superficial fistulae, $84.1 \%$ of inter-sphincteric fistulae and $69.3 \%$ of trans-sphincteric fistulae. The difference was statistically significant. $(p=0.001)$.

To date, the studies done to assess the predictive accuracy of the Goodsall's rule have shown conflicting results [1, 4, 5]. According to a retrospective study of 216 patient records conducted in the 1980s, the predictive accuracy for fistulae with external openings posterior to the transverse anal line was $90 \%$ while for those with external openings anterior to the transverse anal line was 49\% [1]. However, this study did not exclude complex fistulae. In a study conducted in Malaysia from 2010 to 2012, of the 71 patients with fistula-in-ano, 54\% with external opening anterior to the transverse anal line and $53 \%$ with external opening posterior to the transverse anal line complied with Goodsall's rule [4]. Another study of 35 patients conducted in 2000 reported that only 59\% of internal openings were in accordance with Goodsall's rule, but this study also included recurrent fistulae [5].

The reason for the conflicting results in these studies, may be the different proportions of type and the complexity of fistulae included in the sample. Therefore, in our study, we specifically analysed the simple fistulae and determined the predictive accuracy in terms of the type of fistula (eg. superficial, intersphincteric, and transsphincteric) and the position of the external opening. In our study, the predictive accuracy of anterior fistulae was not as low as in some of the studies mentioned above. 
However, those with midline external openings both anteriorly and posteriorly had high predictive accuracy which were $100 \%$ and $97.7 \%$ respectively.

In the current study, superficial fistulae followed by inter-sphincteric fistulae had higher predictive accuracy compared to trans-sphincteric fistulae. Similar results were also elicited in a prospective study done in 2008 by Barwood et al [6]. In that study Goodsall's rule was more accurate for inter-sphincteric fistulae (93\%) than for trans-sphincteric fistulae (68\%) [6].

This study focussed specifically on simple fistulae and reported a predictive accuracy of $78.3 \%$, which means that roughly 1 in 5 fistulae did not comply with the Goodsall's rule. Therefore, surgeons should take precautions to not miss a possible unusual fistula tract, although the fistulae belonged to the "simple" category. As trans-sphincteric tracts had significantly lower predictive accuracy, surgeons should have a higher degree of suspicion regarding deviant pathways, when dealing with trans-sphincteric tracts.

\section{Limitations}

This was a retrospective study, where the anatomy of the fistula tracts was determined mainly using clinical examination, supplemented by imaging. Prospective studies using better imaging techniques may help to delineate the fistula tracts more accurately.

\section{Conclusion}

In our study, $78 \%$ of simple fistulae were compliant with the Goodsall's rule. The predictive accuracy was high in superficial and inter-sphincteric fistulae. Although
Goodsall's rule was not applicable in $22 \%$ of all simple fistulae, it can be used as a guide by surgeons in locating the path of the tract and the internal opening.

\section{Conflicts of interest}

There are no conflicts of interest.

\section{References}

1. Cirocco WC, Reilly JC. Challenging the predictive accuracy of Goodsall's rule for anal fistulas. Dis Colon Rectum 1992; 35: $537-42$.

2. Parks AG, Gordon PH, Hardcastle JD. A classification of fistula-in-ano. Br J Surg 1976; 63: 1-12.

3. Beck DR, Wexner SD, Hull TL, et al. The ASCRS manual of colon and rectal surgery. New York: Springer 2014.

4. Mallick KK, Kamil NBM. Relevance Of Goodsall's Rule In Fistula-In-Ano. Malay; 52: 73.

5. Gunawardhana PA, Deen KI. Comparison of hydrogen peroxide instillation with Goodsall's rule for fistula-in-ano. ANZ J Surg 2001; 71: 472-4.

6. Barwood N, Clarke G, Levitt S, Levitt M. Fistula-in-ano: a prospective study of 107 patients. Australian and New Zealand Journal of Surgery 1997; 67: 98-102.

7. Whiteford MH, Kilkenny J, 3rd, Hyman N, et al. Practice parameters for the treatment of perianal abscess and fistulain-ano (revised). Dis Colon Rectum 2005; 48: 1337-42.

8. Parks AG, Stitz RW. The treatment of high fistula-in-ano. Dis Colon Rectum 1976; 19: 487-99.

9. Mizrahi N, Wexner SD, Zmora O, et al. Endorectal advancement flap: are there predictors of failure? Dis Colon Rectum 2002; 45: 1616-21. 